\title{
Contar histórias: uma proposta de avaliação assistida da narrativa infantil
}

\author{
Alessandra Brunoro Motta \\ Sônia Regina Fiorim Enumo \\ Maria Margarida Pereira Rodrigues \\ Lidiane Leite \\ Universidade Federal do Espírito Santo
}

\begin{abstract}
RESUMO
A linguagem tem um papel central na vida humana, contribuindo para o desenvolvimento de habilidades cognitivas e sociais. Entre as formas de avaliar o comportamento lingüístico infantil, as narrativas têm sido empregadas por meio de atividades como descrever figuras e recontar histórias. A avaliação feita por procedimento assistido em que o avaliador auxilia a criança, após uma fase inicial sem ajuda, testando sem auxílio novamente ao final, tem se mostrado apropriada. Investigando este procedimento, esta pesquisa avaliou a narrativa de 10 crianças de ambos os sexos, com idade entre 5 e 7 anos, freqüentando uma pré-escola pública de Vitória/ES. Foi utilizado um instrumento de avaliação e intervenção assistida da narrativa, o qual avalia aspectos da narração de histórias, por meio de 2 livros de histórias, com desenhos coloridos. Todas as crianças melhoraram a produtividade da história 1 para a história 2 em pelo menos um dos aspectos avaliados. Sobre os componentes, idéias e linguagem e estrutura da narrativa, destacam-se os componentes "informação sobre as personagens" (90\%) e "complexidade do vocabulário" (80\%) pelo percentual de melhora igual ou superior a 80\%. O instrumento mostrou-se adequado à avaliação da narrativa infantil, envolvendo a criança durante a aplicação.

Palavras-chave: avaliação da linguagem; avaliação assistida; narrativa infantil.
\end{abstract}

\section{ABSTRACT \\ Telling stories: a proposal of dynamic assessment of the children narrative}

Language plays a key role in human life, contributing to the development of cognitive and social skills. Among the forms of evaluating the child linguistic behavior, the narratives have been used through activities such as describing illustrations and retelling stories. The evaluation, done by dynamic assessment - including help from the examiner during the process - has proved to be appropriate. Investigating this procedure, this research tested the application of dynamic testing of the narrative in 10 children of both genders, with age between 5 and 7 years, attending to a public preschool of Vitoria/ES. The instrument used evaluates aspects of the narration of stories, using two story books, with colored ilustrations. All the children improved the productivity of the story between the first and second story in at least one of the aspects evaluated. The components "Information about the characters" (90\%) and "Complexity of the Vocabulary" (80\%) presented an increase of $80 \%$ or more. The instrument was proved to be appropriate to the evaluation of the narrative of the children, motivating the child to participate.

Keywords: language assessment; dynamic assessment; child narrative.

$\mathrm{O}$ interesse pelo estudo da linguagem em crianças tem se mantido presente no campo da Psicologia há algum tempo. Desde o trabalho pioneiro de Gesell e Amatruda (Gesell, 2002), no início do século XX, muitos trabalhos foram realizados voltados à descrição do processo de aquisição da linguagem, com destaque para os ganhos característicos de cada fase da infância, relacionando-os aos demais aspectos do desenvolvimento físico, cognitivo e psicossocial (Bee \& Mitchel, 1984; Mussen, Conger, Kagan \& Huston, 1995; Papalia \& Olds, 2000). Resumindo os principais marcos do desenvolvimento da linguagem, temos o balbucio do bebê, que marca o período inicial da linguagem verbal; as primeiras palavras compreensíveis 
surgem aproximadamente aos 12 meses; entre 24 e 30 meses, é possível observar emissões mais longas e complexas; até que, a partir dos 4 anos de idade, a criança já apresenta falas que se relacionam, aproximando-se da fala adulta (Mussen e cols., 1995).

Embora muitos trabalhos tenham se voltado para o estudo do desenvolvimento da linguagem, o tema da avaliação da linguagem ainda é motivo de preocupação devido às limitações relativas à carência de pesquisas sobre o desenvolvimento normal e deficiente da linguagem em crianças, somadas ao pouco conhecimento sobre a sua variabilidade em crianças que apresentam problemas de origem evolutiva (Acosta, Moreno, Ramos, Quintana \& Espino, 2003).

Tais preocupações são pertinentes diante do papel central da linguagem no desenvolvimento das habilidades cognitivas e sociais da criança. Assim, avaliações mal conduzidas poderão gerar diagnósticos duvidosos, comprometendo intervenções clínicas e escolares.

Em revisão teórica e prática do processo de avaliação da linguagem na criança, Acosta e cols. (2003) propõem, como procedimentos e estratégias de avaliação, o uso de testes padronizados, como, por exemplo, o Teste Illinois de aptidões psicolingüísticas (ITPA), o Teste de Vocabulário em Imagens Peabody (TVIP) e os subtestes verbais que medem informação, compreensão, semelhanças e vocabulário da Escala Weschsler de Inteligência (WISC); escalas de desenvolvimento; observação do comportamento e testes não padronizados.

Entre as formas de acessar o comportamento lingüístico infantil, as narrativas têm sido empregadas em processos de avaliação da linguagem, estando inseridas no bloco dos testes não padronizados, com atividades do tipo: descrições de lâminas, recontar histórias, explicação de piadas e adivinhações, entre outras (Acosta e cols., 2003).

Uma das razões pelas quais as narrativas têm sido utilizadas em processos de avaliação da linguagem infantil é sua função preditora dos resultados escolares futuros para aquelas crianças que apresentam riscos acadêmicos e de problemas de linguagem (Paul \& Smith, 1993; Peterson, Jesso \& McCabe, 1999). Além disso, as narrativas estão incluídas na atividade mais geral de contar e ouvir histórias, a qual se relaciona com o desenvolvimento da linguagem, especialmente por permitir a ampliação do vocabulário. Neste caso, as ilustrações contidas nos livros, os gestos, a entonação e o ritmo da leitura favorecem a compreensão do significado de palavras desconhecidas (Whitehurst e cols., 1988).
Ao analisar a constituição das narrativas infantis, verifica-se a presença de uma cadeia principal de eventos, com orações tanto descritivas, responsáveis por relatar o que acontece, quanto de contextualização, as quais fornecem informações sobre os personagens, o cenário e o porquê dos acontecimentos (Eaton, Collis \& Lewis, 1999).

Parece existir, então, uma estrutura de composição de narrativas, responsável por garantir a coerência e o entendimento das histórias. Considerando este aspecto, Labov (citado por Eaton e cols., 1999) desenvolveu um protótipo de estrutura narrativa dentro do qual deve estar incluído: (a) a idéia geral; (b) a orientação; (c) a ação geradora do problema; (d) avaliação; (e) resolução e (f) conclusão. Tal protótipo, inicialmente descrito para narrativas de adultos, tem sido verificado também nas narrativas infantis (Eaton e cols., 1999; Peterson \& McCabe, 1983).

Analisando a presença deste padrão em narrativas de crianças com idade entre 3 e 9 anos, Peterson e McCabe (1983) verificaram que, somente a partir dos 6 anos, é possível identificar os componentes descritos por Labov. Apenas a partir desta idade, as histórias apresentam o movimento em direção à resolução e conclusão, além de ser maior o uso da avaliação, ou seja, de explicações sobre o porquê e como os eventos acontecem.

Em estudo sobre a narrativa de crianças sobre uma sequiência de vídeo sem diálogo, Eaton e cols. (1999) identificaram relações entre a idade e o aumento da inclusão de explanações avaliativas nas histórias, ou seja, as narrativas das crianças maiores contêm informações sobre os estados mentais das personagens e uma maior contextualização dos eventos.

Outro aspecto verificado naquele trabalho relaciona-se ao fornecimento de dicas à criança, por meio de perguntas que eliciem informações sobre tais explanações avaliativas. Este tipo de intervenção considera o conceito de scaffolding ${ }^{1}$, em que o cuidador fornece um apoio, a partir do qual a criança consegue completar a tarefa com sucesso (Eaton e cols., 1999). Assim, foi possível constatar que essas dicas facilitaram a produção de avaliações pelas crianças, encorajandoas a efetuar inferências sobre as ações dos atores na sequiência da história.

Ainda sobre a produção de histórias, Miller, Gillam e Peña (2001) afirmam que as histórias têm um papel central na vida das crianças, de forma que, quando elas têm dificuldades para contar ou de entender histórias, correm o risco de perder aspectos im- 
portantes da comunicação e da aprendizagem. Com base nesta constatação, esses autores criaram um instrumento visando a delinear um processo a partir do qual o clínico seja capaz de conhecer, com precisão, em quais aspectos da narrativa uma criança tem mais dificuldade e, assim, fornecer o apoio adequado para ajudar a criança a aprender como ouvir e contar histórias interessantes e coerentes.

Diante do que foi exposto e considerando a importância do desenvolvimento de processos avaliativos da linguagem de crianças, optou-se por utilizar um modelo de avaliação que permitisse uma interação maior entre a criança e o examinador, como ocorre com a avaliação "assistida", dado seu caráter dinâmico.

Baseada na teoria sócio-cultural do desenvolvimento cognitivo de Vygotsky e na teoria da experiência da aprendizagem mediada de Reuven Feüerstein, a avaliação assistida (dinâmica ou interativa) é uma inovadora abordagem para avaliar habilidades humanas, especialmente o potencial de aprendizagem, indo além da avaliação das realizações presentes. $\mathrm{O}$ formato teste-intervenção-reteste é uma característica da administração de uma avaliação assistida, a partir do qual se verifica a incorporação da intervenção no processo de avaliação (Enumo, Cunha, Paula \& Dias, 2002; Haywood \& Tzuriel, 2002; Lidz \& Peña, 1994; Linhares, 1995; Paula, 2004). Nesse tipo de avaliação, conta-se com o auxílio de perguntas de orientação, exemplos e demonstrações que contribuem para a resolução de tarefas. Entende-se que o aprendizado da criança acontece por meio da interiorização dos resultados de sua interação com o adulto, considerando, principalmente, os conceitos de "aprendizagem mediada" e "zona de desenvolvimento proximal", em que a aprendizagem está focalizada naquilo que a criança está quase pronta a realizar (Papalia \& Olds, 2000).

O conceito de aprendizagem mediada, a partir do qual se considera a importância da interação entre o avaliador e a criança, pode ser mais bem compreendido sob o ponto de vista da Experiência de Aprendizagem Mediada - EAM, descrita por Feüerstein, Rand, Hoffman e Miller (1980). Para esses autores, a EAM enfatiza as experiências de socialização. Estas, por sua vez, têm um papel ativo como facilitadoras do desenvolvimento cognitivo da criança. Sendo assim, crianças que tiveram uma experiência de mediação mais favorável estarão mais aptas para obter maiores ganhos da experiência de aprendizagem.

Com base nos trabalhos clínicos de Feüerstein e cols. a respeito da EAM, Lidz (1991) desenvolveu a
Mediated Learning Experience Rating Scale, a partir da qual realizou adaptações, como a inclusão de mais dois componentes. Esses componentes da mediação avaliados pela escala são descritos a seguir: (a) intencionalidade - atitude consciente e ativa do mediador capaz de influenciar o comportamento da criança, mantendo o seu envolvimento na interação; (b) significação - o mediador explica para a criança porque a tarefa ou o objetivo é importante, ajudando-a a prestar atenção nos aspectos importantes da tarefa e entender a relevância; (c) transcendência - o mediador ajuda a criança a desenvolver consciência metacognitiva da tarefa; tenta transcender ao contexto imediato da tarefa, relacionando-o a conteúdos anteriores ou posteriores; (d) compartilhar (foco compartilhado) - ocorre quando o mediador olha e comenta sobre uma iniciativa da criança, e quando o mediador tenta, figurativa ou literalmente, ver a tarefa do ponto de vista da criança, expressando a qualidade da interação da aprendizagem; (e) compartilhar (compartilhar experiências) o mediador comunica à criança uma experiência relacionada à tarefa ou à situação que o mediador teve $\mathrm{e}$ que a criança não compartilhou, situações estas que têm o efeito potencial de ampliar o repertório de informação da criança, de permitir ao mediador associarse e relacionar-se com a experiência da criança e promover a internalização da aprendizagem da criança por meio de identificação com o mediador; (f) competência (regulação da tarefa) - o mediador manipula a tarefa para facilitar o domínio pela criança; (g) competência (elogio/encorajamento) - o mediador comunica (de modo verbal ou não-verbal) à criança que ela fez um bom trabalho; (h) competência (mudança/zona de desenvolvimento proximal) - inclui a regulação do nível de dificuldade da apresentação da tarefa, para que, de um lado, a criança seja desafiada e encorajada a alcançar além de seu nível de funcionamento corrente, enquanto que, de outro lado, a criança não seja frustrada; (i) diferenciação psicológica - inclui a idéia de que o papel do mediador é facilitar a aprendizagem da criança e não ser uma experiência de aprendizagem para ele, não devendo haver indicações de competição com a criança; (j) responsividade contingente - um mediador que é responsivo de modo contingente está apto para ler os sinais da criança relativos à aprendizagem, às suas necessidades afetivas e emocionais, para, então, responder de forma oportuna e apropria$\mathrm{da}$; $(\mathrm{k})$ envolvimento afetivo - o mediador comunica um senso de carinho e afeto pela criança, promovendo o sucesso da criança na aprendizagem; e (1) mudança - inclui a comunicação à criança de que ela lucrou com a experiência e que o seu produto e comportamentos finais são, de modo significativo, diferentes 
daqueles iniciais. Isso inclui fornecer à criança comparações pré e pós, do que ela produziu antes e depois da intervenção.

Essa escala é aplicada em diversas áreas: como instrumento de diagnóstico clínico, é utilizada em observações de interações pais-filho e professorcriança; em pesquisa, investigam-se suas qualidades psicométricas, e, por fim, tem sido útil no treinamento para avaliadores (Lidz, 1991), tendo sido operacionalizada e aplicada em mães de crianças com deficiência visual, em nosso país (Fonseca, Cunha \& Enumo, 2002).

O modelo da avaliação assistida tem sido amplamente utilizado em crianças com necessidades educativas especiais, especialmente quando o objetivo da avaliação ultrapassa a simples identificação da presença de dificuldades cognitivas, abrangendo também a possibilidade de dimensionar os recursos potenciais de suas habilidades cognitivas (Enumo, 2005; Ferriolli, Linhares, Loureiro \& Marturano, 2001; Tzuriel, 2001).

Em suma, o objetivo desse modelo assistido de avaliação seria descrever as adequações e deficiências do aprendiz, derivar uma impressão da "modificabilidade" (modifiability), induzir a aprendizagem ativa e auto-reguladora, determinar o nível de intensidade necessária para produzir mudanças, e experimentar intervenções que demonstrem efetividade ou falta de efetividade em induzir melhora do desempenho (Lidz, 1991).

$\mathrm{Na}$ área da linguagem especificamente, Lidz e Peña (1994) realizaram um estudo, com crianças préescolares, no qual adaptaram o uso do modelo de avaliação assistida para a diferenciação entre "distúrbios de linguagem" e "diferenças de linguagem", obtendo sucesso ao verificar que a responsividade da criança à intervenção inserida na avaliação, ofereceu uma base mais significativa para o diagnóstico do que a avaliação estática (psicométrica tradicional).

Peña, Iglesias e Lidz (2001) chegaram a resultados similares em pesquisa sobre o desempenho de crianças pré-escolares de cultura e língua diferentes, em uma tarefa de aprendizagem de palavras. Este estudo indicou que a aplicação da avaliação assistida, utilizando as estratégias da aprendizagem mediada, é adequada, permitindo também a diferenciação entre diferença de linguagem e distúrbio de linguagem.

Para finalizar, Miller e cols. (2001) afirmam a importância da avaliação assistida da narrativa, a partir das seguintes justificativas: (a) ajuda na diferenciação entre diferença de linguagem e distúrbio de linguagem; (b) são orientados para avaliação e intervenção, e apresentam um caráter interativo; (c) enfatiza o esforço de ensino e a responsividade da criança; (d) tem se mostrado mais adequada do que a avaliação estática da linguagem; e (e) guia o processo de intervenção.

Diante dessas constatações e considerando o importante papel da linguagem no desenvolvimento da criança, é que se pretendeu, na presente pesquisa, investigar a narrativa de crianças pré-escolares, por meio de um procedimento assistido.

\section{MÉTODO}

\section{Participantes e local de coleta de dados}

Participaram desta pesquisa 10 crianças (5 meninas e 5 meninos), com idade entre 5 e 7 anos (média de 5 anos e 9 meses), freqüentando um Centro de Educação Infantil Municipal de Vitória, ES. A escolaridade variou entre o Jardim e o Pré da Pré-escola (50\% no Jardim-de-Infância e 50\% no Pré-primário). Nenhuma criança tinha indicação de dificuldade de linguagem.

\section{Material e instrumentos}

Para a coleta de dados, foram utilizados como instrumentos:

1) Ficha de identificação da criança - para coleta de dados referentes à idade e escolaridade da criança.

2) Instrumento de Avaliação e Intervenção Dinâmica da Narrativa (Miller e cols., 2001), traduzido para o português para fins de pesquisa. Trata-se de um instrumento que permite avaliar os principais aspectos da narração de histórias: (a) os componentes da história (cenário, informação sobre personagens, ordem temporal dos eventos e relações causais), (b) idéias e linguagem da história (complexidade de idéias, complexidade de vocabulário, complexidade gramatical, conhecimento do diálogo e criatividade) e (c) estrutura do episódio (episódio básico, episódio completo e episódio múltiplo). Este instrumento descreve o processo de avaliação dinâmica de narrativas, bem como o processo de intervenção por meio da aprendizagem mediada. O instrumento contém um manual de aplicação, 2 livros de história sem palavras, com desenhos coloridos estilizados: "Dois amigos" e "O pássaro e seu anel", e um protocolo de registro das histórias contadas. 
O enredo do primeiro livro - Dois amigos - pode ser assim resumido: um cachorro e uma gata estão conversando, e o cachorro dorme. A gata espera o cachorro acordar e, diante da demora, fica com raiva e sai. Quando o cachorro acorda e percebe que a gata não está no local, sai à sua procura, perguntando por ela aos animais que encontra no caminho. Após atravessar um rio, o cachorro enxerga o rabo da gata e segue em sua direção. O cachorro e a gata se encontram novamente e voltam a conversar.

O pássaro e seu anel é a história do segundo livro, cujo enredo relata a história de um pássaro que encontra um anel e leva-o até seu ninho, onde está o seu filhote. Deixa o anel no ninho e sai. Encontra uma lagartixa, fala sobre o anel e leva-a até o ninho. Chegando lá, o pássaro percebe que o anel não está mais no ninho e sai à sua procura, perguntando para os animais que encontra no caminho sobre o anel. Ao retornar ao seu ninho, percebe que o anel está atrás do tronco da árvore. Pega-o de volta e retorna ao ninho.

A aplicação do instrumento de avaliação assistida da narrativa consiste na apresentação do livro Dois amigos para a criança, que, em seguida, é solicitada a contar uma história sobre o mesmo. Após o registro e a análise dos dados da história da criança em protocolo de registro específico, são selecionados objetivos para a sessão de avaliação mediada, na qual a criança recebe "dicas" ou pistas para melhorar suas habilidades narrativas. Assim, cada sessão de avaliação mediada é composta por, no mínimo, cinco destas sete estratégias: (a) intenção de ensino- ajudar a criança a entender o objetivo de cada sessão; (b) significadoajudar a criança a dizer por qual razão o objetivo é importante nas histórias; (c) exemplo - encorajar sua criação de exemplos para ilustrar o objetivo; (d) transcendência - guiar a criança a fazer hipóteses além da história Dois amigos, para sua própria vida ou para uma situação imaginária; (e) auto-avaliação - mostrar a criança como avaliar seu próprio aprendizado até o momento; (f) planejamento - ajudar a criança a criar um plano para incorporar o objetivo em suas próprias atividades de história; e (g) transferência - assistir a criança a levar sua habilidade narrativa recém-aprendida além da sessão. Tais estratégias estão baseadas nos componentes da mediação descritos por Lidz (1991).

Por fim, a criança é solicitada a contar uma história sobre o livro $O$ pássaro e seu anel, e, a partir da análise da história e comparação com o desempenho na história Dois amigos, será possível verificar a modificabilidade da habilidade narrativa da criança, assim como sua responsividade à mediação.

\section{Procedimento}

Foram executadas 2 etapas descritas a seguir.

Etapa 1 - Identificação e caracterização dos participantes - As crianças foram identificadas e caracterizadas a partir do registro de matrícula e contato com a professora.

Etapa 2 - Aplicação do instrumento de avaliação dinâmica da narrativa - foi realizada individualmente, em espaço disponibilizado pela escola, com a duração de 3 sessões gravadas em áudio com cada criança: Sessão 1 - Coleta da História 1 (pré-teste), Sessão 2Avaliação Mediada, e Sessão 3 - Coleta da História 2 (pós-teste).

\section{Processamento e análise dos dados}

Foram transcritas as gravações das histórias 1 e 2 e das sessões de avaliação mediada.

O processamento e análise das sessões de avaliação mediada e das sessões de coleta da história seguiram os critérios propostos pelo instrumento (Miller e cols., 2001), calculando-se a produtividade das histórias 1 e 2 ; o percentual de mudança, por meio da subtração da pontuação do pré-teste pela pontuação do pós-teste e depois dividindo pela pontuação do préteste; e a taxa de ganho ${ }^{2}$ das mesmas, verificando-se a significância estatística das diferenças encontradas no grupo.

\section{Análise de riscos e benefícios}

A participação das crianças na pesquisa só ocorreu após autorização do responsável, em consonância com a Norma 196/96 da Comissão Nacional de Ética em Pesquisa - CONEP/Conselho Nacional de Saúde/Ministério da Saúde, e autorização do Comitê de Ética da universidade.

\section{RESULTADOS}

\section{Resultados referentes à produtividade da história}

A Tabela 1 apresenta os dados relativos à produtividade da história, em que são incluídos aspectos como: número de palavras; Unidade-C (oração principal e suas modificações); Unidade-MLC (quantidade de informação léxica e gramatical que a criança inclui na expressão vocal); Orações e Orações/Unidade-C (medida da complexidade da sentença). 
Tabela 1: Comparação da produtividade média da narrativa entre as histórias 1 e 2 ( $n=10)$

\begin{tabular}{lcccc}
\hline Categorias da narrativa & História 1 & História 2 & Taxa de ganho & p-valor \\
\hline Palavras & 91,9 & 152,3 & 65,7 & $0,009^{\star *}$ \\
AV & $(55-125)$ & $(96-238)$ & & $0,010^{*}$ \\
Unidade-C & 12,9 & 16,4 & 27,1 & \\
AV & $(11-15)$ & $(12-21)$ & & $0,022^{*}$ \\
Unidade MLC & 7,1 & 9,3 & 30,4 & \\
AV & $(5-9.3)$ & $(6.8-12.5)$ & $5,009^{* *}$ \\
Orações & 19,5 & 29,8 & \\
AV & $(16-24)$ & $(20-41)$ & & $0,047^{*}$ \\
Orações/Unidade-C & 1,5 & 1,8 & 20 & \\
AV & $(1.1-1.8)$ & $(1.2-2.4)$ & & \\
\hline${ }^{*} p \leq 0.05 ;{ }^{* *} p \leq 0.01 ;$ Teste de Wilcoxon; AV: amplitude de variação; Unidade-C: oração principal e suas modificações; Unidade-MCL: quantidade \\
de informação léxica e gramatical que a criança inclui na expressão vocal.
\end{tabular}

A análise dos dados, por meio de estatística nãoparamétrica, com o Teste de Wilcoxon, comparando as narrativas das histórias 1 e 2, demonstrou uma melhoria significativa $(p \leq 0,05)$ da produtividade intragrupo, em todos os aspectos avaliados. Destacam-se as taxas de ganho na frequiência média de palavras $(65,7 \%)$ e de orações $(52.8 \%)$ ditas pelas crianças. Os dados indicam melhora na eficiência das crianças, o que pode ser atribuído ao processo de mediação.
Analisando a produtividade de cada criança (Tabela 2), destaca-se a melhora na eficiência de C8 (aumento nas categorias - Palavras: 124,5\%; Unidade-C: 58,3\%; Unidade-MLC: 42\%; Orações: 141,2\% e Orações/Unidade-C: $50 \%$ ) e C10 (Palavras: 154,5\%; Unidade-C: 63,7\%; Unidade-MLC: $56 \%$; Orações: $100 \%$ e Orações/Unidade-C: $28,6 \%$ ), com taxas de ganho de $100 \%$ de aumento na produção de palavras e de orações.

Tabela 2: Produtividade das histórias em termos de freqüência nas histórias 1 e 2, por criança

\begin{tabular}{ccccccccccc}
\hline Categoria & \multicolumn{2}{c}{ Palavras } & \multicolumn{2}{c}{ Unidade-C } & \multicolumn{2}{c}{ Unidade-MLC } & Orações & \multicolumn{2}{c}{$\begin{array}{c}\text { Orações/ } \\
\text { Unidade-C }\end{array}$} \\
\hline História & 1 & 2 & 1 & 2 & 1 & 2 & 1 & 2 & 1 & 2 \\
Criança & & & & & & & & & & \\
\hline C1 & 121 & 181 & 13 & 16 & 9,3 & 11,3 & 23 & 35 & 1,8 & 2,2 \\
C2 & 78 & 131 & 14 & 14 & 5,6 & 9,3 & 18 & 25 & 1,3 & 1,8 \\
C3 & 85 & 96 & 13 & 12 & 6,5 & 8 & 19 & 21 & 1,5 & 1,7 \\
C4 & 94 & 179 & 14 & 16 & 6,7 & 11,2 & 16 & 33 & 1,1 & 2,1 \\
C5 & 92 & 132 & 11 & 13 & 8,4 & 10,1 & 20 & 31 & 1,8 & 2,4 \\
C6 & 83 & 148 & 15 & 21 & 5,5 & 7 & 23 & 28 & 1,5 & 1,3 \\
C7 & 125 & 110 & 14 & 16 & 8,9 & 6,9 & 24 & 20 & 1,7 & 1,2 \\
C8 & 106 & 238 & 12 & 19 & 8,8 & 12,5 & 17 & 41 & 1,4 & 2,1 \\
C9 & 80 & 168 & 12 & 19 & 6,7 & 8,8 & 19 & 32 & 1,6 & 1,7 \\
C10 & 55 & 140 & 11 & 18 & 5,0 & 7,8 & 16 & 32 & 1,4 & 1,8 \\
Média & 91,9 & 152,3 & 12,9 & 16,4 & 7,1 & 9,3 & 19,5 & 29,8 & 1,5 & 1,8 \\
Md & 88,5 & 144 & 13 & 16 & 6,7 & 9,1 & 19 & 31,5 & 1,5 & 1,8 \\
\hline
\end{tabular}

Unidade-C: oração principal e suas modificações; Unidade-MLC: quantidade de informação léxica e gramatical que a criança inclui na expressão vocal.

Observa-se também que $\mathrm{C} 3$ apresentou um decréscimo do número de Unidades-C (oração principal e suas modificações), associado, porém, a um aumento da Unidade-MLC (quantidade de informação léxica e gramatical que a criança inclui na expressão vocal), indicando uma melhora na eficiência da criança, uma vez que ela usou menos Unidades-C, mas, estas, no geral, foram mais longas.

Analisando a produtividade de C7, observa-se um decréscimo em todos os aspectos avaliados, exceto na 
freqüência de Unidades-C, podendo resultar na diminuição da eficiência da criança. Entretanto, a análise dos componentes da narrativa de suas histórias indicou melhora naqueles focalizados na mediação.

\section{Resultados referentes aos componentes e processoas da história}

A Tabela 3 apresenta o número de crianças que melhoraram, pioraram ou não alteraram os processos e componentes da narrativa entre as histórias 1 e 2, destacando-se a melhora nos componentes "Cenário" (8), "Informação sobre as personagens" (9) e "Complexidade do Vocabulário" (8), ressaltando que esses dois últimos componentes, somados ao componente "Conhecimento do diálogo" (6), foram justamente aqueles focalizados na maioria das sessões de mediação pela aplicadora.

Tabela 3: Número de crianças que alteraram os processos/componentes da narrativa entre as histórias 1 e $2(n=10)$

\begin{tabular}{lccc}
\hline $\begin{array}{l}\text { Processos/ } \\
\text { Componentes da narrativa }\end{array}$ & Melhor & Pior & Não mudou \\
\hline Cenário & 8 & 1 & 1 \\
Informações sobre personagens & 9 & & 1 \\
Ordem temporal dos eventos & 4 & 4 & 2 \\
Relações causais & 5 & 2 & 3 \\
Complexidade de idéias & 5 & 1 & 4 \\
Complexidade do vocabulário & 8 & - & 2 \\
Complexidade gramatical & 7 & 1 & 2 \\
Conhecimento do diálogo & 6 & 1 & 3 \\
Criatividade & 7 & - & 3 \\
\hline
\end{tabular}

Quando se analisa o componente - "Resposta Interna", verifica-se que 6 crianças pioraram da história 1 Dois amigos para a história 20 pássaro e seu anel. No entanto, este fato pode ser justificado pela constatação de que, na história 1 Dois amigos, a personagem Gata apresenta uma expressão facial que indica explicitamente um sentimento, facilitando a identificação da "Resposta Interna". Já na história $2 O$ pássaro $e$ seu anel, não existe a expressão direta de emoções pelas personagens.

A "Resposta Interna", juntamente com o "Evento desencadeador", a "Tentativa", o "Plano", a "Consequência" e o "Final" constituem a Estrutura do episódio, elementos estes que vão contribuir para a garantia de uma história coerente e completa. Avaliando este aspecto da narrativa, verificou-se que embora metade (40\%) das crianças tenha apresentado melhora no desempenho deste aspecto, a outra metade (40\%) piorou e $20 \%$ não apresentou alteração do pré-teste para o pós-teste.

Procurando ressaltar a aplicação clínica do instrumento proposto e ilustrar os dados apresentados anteriormente, será apresentada, a seguir, a descrição de uma avaliação.

\section{Descrição de Caso}

Maria é uma menina de 5 anos e 7 meses, que mora na Grande Vitória, com seus pais. Está matriculada na pré-escola de um Centro Municipal de Educação Infantil de Vitória/ES.

\section{Passo 1: Coletar a história Dois amigos}

Após contato inicial com a criança, o livro Dois amigos foi apresentado a Maria. A criança foi orientada a olhar com calma todo o livro, observando atentamente as imagens apresentadas, para que depois contasse a história. Embora Maria tenha cumprido a orientação de folhear o livro com calma, ela não fazia pausas para observar por mais tempo cada uma das ilustrações. Ainda antes do início da história, a criança foi incentivada e orientada a contar a melhor história que pudesse, com a ressalva de que não havia história certa ou errada.

A narrativa de Maria sobre a história Dois amigos, transcrita para o Formulário de Registro da História, foi a seguinte: "Aqui, é um cachorrinho dando um papel escrito para o outro. Aí, o leão deu um outro papelzinho para ele também. $O$ gatinho ficou com raiva. Aí, o leão deu outro pra ele; aí, ele foi embora. Aí, o leão fez outro; aí, o outro ele gostou. Aí, o ca- 
chorrinho, ele lembrou do amigo dele. Aí, ele foi lá visitar o amigo. E encontrou o amigo e deu uma cartinha pra ele. Aí, ele encontrou um bichinho e fez uma outra cartinha e deu pra ele. Aí o cãozinho foi nadar com os peixinhos. Depois, ele encontrou o amiguinho dele. E aí, foi pra casa dele".

\section{Passo 2: Pontuando a História 1}

Maria ${ }^{4}$ usou um total de 106 palavras, 17 orações e 12 unidades-C na história 1. Para calcular a quantidade de informação léxica e gramatical que a criança incluiu na expressão vocal (Unidade-MLC), o número de palavras foi dividido pelo número total de Unidades-C, obtendo-se o valor de 8,88. A medida da complexidade da sentença foi 1,42 , calculada a partir da divisão do número de orações pelo número total de Unidades-C.

Passo 3: Classificando os componentes e processos da História

A classificação dos "Componentes da história" e das "Idéias e linguagem da história" mostrou que a história da criança foi bem pontuada na maioria dos itens, exceto Informações sobre os personagens e Conhecimento do diálogo, os quais não receberam nenhuma pontuação.

Embora a narrativa da criança tenha ido além da pura descrição das ilustrações, o roteiro seguido não se relacionava ao conteúdo que as imagens deveriam transmitir. Um fator foi decisivo para que a história de Maria tivesse outro sentido: a presença de onomatopéias, ou seja, balões indicativos de diálogo, sentimentos ou estados fisiológicos. Para a criança, esses balões foram entendidos como cartas, como é possível verificar na expressão: "E encontrou o amigo e deu uma cartinha pra ele". Não houve preocupação em verificar o conhecimento deste conteúdo junto à criança, uma vez que não havia indicação no manual. Optouse, então, por oferecer informações sobre este aspecto durante as sessões de avaliação mediada.

No que se refere à "Estrutura do episódio", foi possível identificar o evento desencadeante: "o cachorrinho, ele lembrou do amigo dele"; a tentativa: "aí ele foi lá visitar o amigo"; a conseqüência: "e encontrou o amigo e deu uma cartinha pra ele"; caracterizando assim, um episódio básico. A presença de mais dois elementos, a resposta interna e a reação/fim, garantiu a classificação do episódio como: "Episódio básico + 2 elementos".
Passo 4: Planejando e Conduzindo as Sessões de Avaliação Mediada

O critério utilizado para a seleção do foco da sessão de mediação foi trabalhar com o compontente e/ou processo que não recebeu pontuação ou recebeu uma pontuação inferior. No caso de Maria, foram selecionados os únicos itens que não receberam pontuação: Informação sobre os personagens e Conhecimento do diálogo. Foram realizadas 02 sessões, com duração total de 21 minutos, gravadas em áudio. Ainda para a realização das sessões, foi feito o preenchimento das fichas Estratégias de Avaliação Mediada para cada um dos componentes selecionados, com o objetivo de planejar as sessões, identificando as estratégias de mediação a serem utilizadas, bem como os recursos que poderia utilizar para ajudar Maria a melhorar o desempenho daqueles componentes e, como consequência, da narrativa de modo geral.

Para a mediação da narrativa, foram utilizados como suporte: explicações, exemplos, questionamentos, elogios, redirecionamentos e modelos a partir de livros de literatura infantil: Branca de Neve (Grimm, 1995a) e Rapunzel (Grimm, 1995b). Por meio desses suportes, foram empregadas todas as sete estratégias de ensino mediado propostas pelos autores do instrumento.

Durante as sessões de avaliação mediada, Maria exigiu pouco esforço de ensino, não sendo necessário estender a sessão com muitos exemplos e explicações. Sua responsividade foi avaliada como alta, já que precisou de pouco suporte para seguir as orientações e compreender as estratégias ensinadas. $\mathrm{Na}$ sessão Conhecimento do Diálogo, por exemplo, quando se emprega a estratégia "Exemplo", encorajando a criança a criar um diálogo em uma das ilustrações da história Dois amigos, Maria executou a tarefa adequadamente, incluindo tons de voz diferentes para cada um dos personagens e transcendendo o aprendizado, uma vez que passou a lembrar de outras histórias que já conhecia e que continham diálogo.

\section{Passo 5: Coletando a História 2}

Seguindo o mesmo procedimento da coleta da história Dois amigos, Maria folheou o livro $O$ pássaro e seu anel, para depois contar a história. Maria demonstrou certa preocupação em relação ao seu desempenho na narrativa da história 2 , quando verbalizou interesse em lembrar o que havíamos conversado nas sessões anteriores. 
A história $O$ pássaro e seu anel narrada pela criança foi transcrita e, posteriormente pontuada em termos de sua produtividade. Sendo assim, foram registradas 238 palavras, 41 orações e 19 Unidades-C, indicando um aumento em produtividade. A quantidade de informação léxica e gramatical foi calculada em 12,53 e a complexidade da sentença 2,16.

A narrativa de Maria foi a seguinte: "Aí, a Juju encontrou um anel brilhante. Aí, ela escondeu lá no lugar que ela poderia ficar sempre olhando lá, o anel. Aí, ela colocou na árvore onde tinha um passarinho. Um passarinho, que o nome dele é Natiele. Aí, a Juju foi embora pra casa dela. Aí, a Natiele ficou com o anel. Aí, ela falou com a iguana se ela viu o anel por aqui: - Você viu o anel por aqui? Aí, depois ela lembrou que tava com o pássaro, mas só que ela não viu o anel. Aí, depois ela foi lá na árvore, encontrou um pipa, um pássaro, que o bico dele que parece uma pipa. Aí ela encontrou um passarinho e falou assim: - Você viu o anel por aí? O anel era amarelo e rosa e tinha umas corzinha azul. Mas, só que foi lá a Juju, e a iguana perguntou lá pro outro passarinho se ele viu o anel por aí. Mas, só que ele falou que não viu. Aí, ela foi olhar lá na árvore onde tinha aquele ninho, só que não encontrou o ninho nem o passarinho. Mas, depois, do outro lado da árvore, ela encontrou o ninho e aquele mesmo passarinho. E, depois, ele olhou pra baixo e viu o anel. E falou pro passarinho assim: - Eu mandei você ficar com o anel! Aí, ele falou assim: - Mas, ele caiu da árvore. Mas, eu não queria ir lá pegar."

No que se refere aos componentes e processos da história, verificou-se que os objetivos focalizados nas sessões de avaliação mediada - informação sobre os personagens e conhecimento do diálogo - apresentaram uma pontuação melhor na história 2. As sentenças “...Um passarinho, que o nome dele é Natiele" e "E falou pro passarinho assim: - Eu mandei você ficar com o anel?", respectivamente, exemplificam a inclusão dos componentes focalizados. Além disso, comparando a pontuação nos demais componentes, constatou-se que Maria apresentou melhora em todos eles. Não houve alteração na estrutura do episódio, a qual manteve a classificação de "episódio básico +2 elementos".

De modo geral, o desempenho de Maria na produção de narrativa, durante o procedimento de avaliação assistida, apresentou melhora tanto de produtividade quanto de conteúdo e coerência, especialmente nos elementos mediados.

\section{DISCUSSÃO}

Esta pesquisa se propôs a investigar a narrativa de crianças pré-escolares, a partir de um procedimento assistido, apresentando uma descrição de um caso para ilustrar as possibilidades de uso clínico do instrumento utilizado.

Considerando que a avaliação da narrativa envolve, principalmente, a análise da dimensão semântica da linguagem (vocabulário expressivo e compreensivo), é importante ressaltar que Acosta e cols. (2003) chamam a atenção para a dificuldade em apresentar padrões evolutivos relativos a esta dimensão, uma vez que variáveis contextuais impedem o estabelecimento de um desenvolvimento típico por idade. Mesmo assim, em revisão teórica sobre o tema, esses autores organizaram séries de padrões evolutivos relativos à compreensão e produção, os quais foram tomados como base para as discussões apresentadas neste artigo.

Assim, em relação ao uso do vocabulário figurativo - um dos aspectos avaliados e mediados pelo instrumento - a literatura indica que somente entre os $8 \mathrm{e}$ 11 anos de idade é que se observa o uso de conceitos verbais que vão além daquilo a que se referem normalmente (Acosta e cols., 2003). Entretanto, análises individualizadas da modificabilidade permitiram constatar mudanças positivas na eficiência do uso do vocabulário em crianças pré-escolares, levando a acreditar que o suporte oferecido durante as sessões de mediação contribuiu para essa melhora.

Em termos metodológicos, o estilo dos desenhos das histórias, especialmente no livro Dois amigos, não oferece muitas pistas sobre o local em que as histórias acontecem. Esta constatação poderia justificar um alto número de intervenções focalizadas no componente da narrativa relacionado ao cenário, o qual, por sua vez, mostra-se básico nas histórias infantis. Além disso, crianças nessa faixa etária já apresentam uma habilidade comunicativa mais elaborada, sendo capaz de compreender e utilizar advérbios de tempo e lugar. Entretanto, nessa mesma faixa etária, verifica-se que a aquisição do significado léxico das palavras acontece, inicialmente, com a aprendizagem de referentes ligados a objetos que se movem, como, por exemplo, animais e pessoas, de forma que nomes de lugares e objetos estáticos são adquiridos mais tarde (Acosta e cols., 2003). Talvez, por isso, as crianças desta pesquisa não demonstraram ter se fixado em aspectos do local, direcionando sua atenção às ações das personagens.

Neste caso, a proposta da avaliação assistida e de ensino mediado mostrou-se adequada, na medida em 
que esse fato não se repetiu no livro com a história $O$ pássaro e seu anel, quando as crianças já haviam passado por sessões de mediação. Nessas sessões de mediação, focalizou-se a importância de falar sobre o cenário quando se conta uma história. A mediação permitiu, então, que a criança ampliasse o uso de seu repertório lingüístico, principalmente em termos de sua produção.

Um outro aspecto a ser considerado, especialmente por ter gerado dúvidas no momento da aplicação do instrumento, foi o desconhecimento de onomatopéias pelas crianças. Diante disso, optou-se por explicar para a criança o seu significado somente na sessão de avaliação mediada, o que pareceu ter prejudicado a compreensão de alguns aspectos da história Dois amigos. Sugere-se, então, a explicação antecipada do significado de uma onomatopéia, quando a criança demonstra não compreendê-la. Tal atitude não prejudicaria a aplicação do instrumento e a análise posterior, uma vez que este aspecto da linguagem não corresponde a nenhum dos componentes da narrativa avaliados pelo instrumento.

No que se refere à composição das narrativas, verificou-se que, no pré-teste, quando as crianças contaram a história Dois amigos, foi comum a presença de orações puramente descritivas da imagem, uma das características da narração de histórias, conforme indicado por Eaton e cols. (1999). Por outro lado, a presença de explanações mais completas e contextualizadas sobre os personagens, o cenário e as justificativas para os acontecimentos só estiveram mais presentes na segunda história.

Ao mesmo tempo em que as crianças incluíram novas informações em suas narrativas, estas não foram suficientes para que a estrutura do episódio da maioria das histórias fosse avaliada como "episódio completo". Neste caso, é preciso considerar que as crianças deste estudo apresentam idade média de 5 anos e 9 meses, ou seja, elas ainda estão desenvolvendo tais habilidades. Desse modo, é como se elas tivessem as ferramentas - um vocabulário extenso e habilidades gramaticais complexas - porém, ainda é necessário o aprimoramento dos componentes que vão garantir a articulação dessas informações, de modo a tornar a história cada vez mais completa e coerente. Neste caso, a atividade de contar histórias provenientes de livros ou mesmo narrar acontecimentos descontextualizados, cumpre um papel muito importante no desenvolvimento da linguagem, devendo ser incentivada junto às crianças e promovida de modo a gerar o interesse nas mesmas.
Em se tratando de um instrumento para uso clínico, sua aplicação no contexto de pesquisa exigiu adaptações operacionais relativas ao tempo e ao número de sessões de mediação, os quais tiveram que ser restritos, assim como o material utilizado na mediação, já que o campo da pesquisa não disponibilizava espaço reservado para esse fim. A otimização dessa situação poderia gerar um aumento ainda mais significativo na produtividade da criança, embora seja verificável que efeitos produzidos já tenham indicado a importância do instrumento para a avaliação da narrativa.

Concluindo, o caráter lúdico do material proposto - livros para contar histórias - mostrou ser capaz de envolver e motivar a participação da criança na pesquisa, como foi possível verificar em seus relatos, na maior parte deles positivos, sobre a ilustração dos livros e enredo das histórias.

\section{REFERÊNCIAS}

Acosta, V. M., Moreno, A., Ramos, V., Quintana, A. \& Espino, O. (2003). Avaliação da linguagem: Teoria e prática do processo de avaliação do comportamento lingüístico infantil. São Paulo: Santos Editora.

Bee, H. L. \& Mitchell, S. K. (1984). A pessoa em desenvolvimento. São Paulo: Harper \& Row do Brasil.

Eaton, J. H., Collis, G. M. \& Lewis, V. A. (1999). Evaluative explanations in children's narratives of a video sequence without dialogue. Journal of Child Language, 26, 699-720.

Enumo, S. R. F. (2005). Avaliação de crianças com necessidades educativas especiais em situação de pesquisa-intervenção: Dificuldades e algumas soluções. Em H. Guilhardi \& N. C. Aguirre (Orgs.), Sobre comportamento e cognição: Expondo a variabilidade (v. 16, pp. 310-330). Santo André: ESETec.

Enumo, S. R. F., Cunha, A. C. B., Paula, K. M. P. \& Dias, T L. (2002). Comportamentos do mediador e da criança com deficiência visual na avaliação assistida de habilidades cognitivas. Temas em Psicologia, 10(1), 71-84.

Ferriolli, S. H. T., Linhares, M. B. M., Loureiro, S. R. \& Marturano, E. M. (2001). Indicadores de potencial de aprendizagem obtidos através da avaliação assistida. Psicologia: Reflexão e Crítica, 14(1), 35-43.

Feüerstein, R., Rand, Y., Hoffman, M. B. \& Miller, R. (1980). Instrumental enrichment. Baltimore: University Park Press.

Fonseca, V., Cunha, A. C. B. \& Enumo, S. R. F. (2002). O desenvolvimento cognitivo da criança com deficiência visual e suas perspectivas de avaliação: Da abordagem padronizada à avaliação dinâmica. Revista de Educação Especial e Reabilitação. (Lisboa), 9(1-2), 75-91.

Gesell, A. (2002). Gesell e Amatruda diagnóstico do desenvolvimento: Avaliação e tratamento do desenvolvimento neuropsicológico do lactente e na criança pequena, o normal e o patológico. São Paulo: Atheneu

Grimm, I. (1995a). Coleção clássicos infantis: Branca de Neve. São Paulo: Paulus. 
Grimm, I. (1995b). Coleção clássicos infantis: Rapunzel. São Paulo: Paulus.

Haywood, H. C. \& Tzuriel, D. (2002). Applications and challenges in dynamic assessment. Peabody Journal of Education, 77(2), 40-63.

Lidz, C. S. (1991). Practitioner's guide to dynamic assessment. New York: The Guilford Press.

Lidz, C. S. \& Peña, E. D. (1994). Dynamic assessment: The model, its relevance as a nonbiased approach, and its aplication to latino-american preschool children. Language, Speech, and Hearing Services in Schools, 27, 367-372.

Linhares, M. B. M. (1995). Avaliação assistida: Fundamentos, definição, características e implicações para a avaliação psicológica. Psicologia: Teoria e Pesquisa, 11(1), 23-31.

Miller, L., Gillam, R. B. \& Peña, E. D. (2001). Dynamic assessment and intervention: Improving children's narrative abilities. Austin, Texas: Proed.

Mussen, P. H., Conger, J. J., Kagan, J. \& Huston, A. C. (1995). Desenvolvimento e personalidade da criança ( $3^{\mathrm{a}}$ ed.). São Paulo: Harbra.

Papalia, D. E. \& Olds, S. W. (2000). Desenvolvimento humano. Porto Alegre: Artes Médicas.

Paula, K. M. P. (2004). Avaliação assistida: Análise de indicadores cognitivos, comportamentais e afetivo-motivacionais em crianças na situação de intervenção com sistema de comunicação alternativa. Tese de Doutorado, Universidade Federal do Espírito Santo. Vitória, ES.
Paul, R. \& Smith, R. L. (1993). Narrative skills in 4-year-olds with normal, impaired, and late developing language. Journal of Speech and Hearing Research, 36, 592-598.

Peña, E., Iglesias, A. \& Lidz, C. S. (2001). Reducing test bias through dynamic assessment of children's word learning ability. American Journal of Speech-Language Pathology, 10, 138-154.

Peterson, C. \& McCabe, A. (1983). Developmental psycholinguistics - three ways of looking at a child's narrative. New York: Plenum.

Peterson, C., Jesso, B. \& McCabe, A. (1999). Encouraging narratives in preschoolers: an intervention study. Journal of Child Language, 26, 49-67.

Tzuriel, D. (2001). Dynamic assessment of young children. New York: Kluwer Academic/Plenum Publishers.

Whitehurst, G. J., Falco, F. L., Lonigan, C. L., Fischel, J. E., Debarysche, B. D., Valdez-Menchaca, M. C. \& Caulfield, M. (1988). Accelerating language development through picture book reading. Developmental Psychology, 24, 552-559.

Recebido: 30/01/2006 Revisado: 05/04/2006 Aceito: 07/07/2006

\section{Notas:}

${ }^{1}$ O conceito de scaffolding foi introduzido por Wood, Bruner e Ross (1976, citados por Eaton e cols., 1999) para descrever os meios pelos quais os cuidadores modificam a tarefa dada à criança pequena, guiando a sua atenção em direção aos aspectos relevantes da tarefa.

$$
\text { Taxa de ganho }=\frac{\text { História } 2}{\text { História } 1} \times 100-100
$$

${ }^{3}$ Resposta interna: elemento do episódio da história que se refere à informação sobre as principais reações ou sentimentos do personagem sobre o evento iniciante (Miller e cols., 2001).

${ }^{4}$ A produtividade de Maria nas histórias 1 e 2 pode ser verificada na Tabela 2, na qual esta criança é identificada como C8.

\section{Sobre os autores:}

Alessandra Brunoro Motta: Doutoranda em Psicologia pela UFES/ES. Programa de Pós-Graduação em Psicologia da Universidade Federal do Espírito Santo/UFES.

Sônia Regina Fiorim Enumo: Prof ${ }^{a}$. Dr ${ }^{a}$. do Departamento de Psicologia Social e do Desenvolvimento e do Programa de PósGraduação em Psicologia da Universidade Federal do Espírito Santo/UFES; pesquisadora do CNPq.

Maria Margarida Pereira Rodrigues: Prof ${ }^{a}$. Dr ${ }^{a}$. do Departamento de Psicologia Social e do Desenvolvimento e do Programa de PósGraduação em Psicologia da Universidade Federal do Espírito Santo/UFES.

Lidiane Leite: Graduanda em Psicologia, Universidade Federal do Espírito Santo, bolsista de Iniciação Científica do CNPq.

Endereço para correspondência: Alessandra Brunoro Motta - Rua Vicente de Oliveira, 13, Mata da Praia - 29066-260 Vitória/ES. Endereço eletrônico: alessandrabmotta@yahoo.com.br. 